\title{
Adoption and use of energy-monitoring technology in ship officers' communities of practice
}

\author{
Martin Viktorelius $^{1}$ (D)
}

Received: 30 January 2019 / Accepted: 18 June 2019 / Published online: 27 June 2019

(c) The Author(s) 2019

\begin{abstract}
The paper offers an analysis of how an energy-monitoring system was implemented and eventually adopted by the crew members in a shipping company. It illustrates how the social process of enacting the system as a collaborative technologyin-practice, enabling a significant reduction in energy consumption, was contingent on the negotiation of meaning and mutual learning among crew members in their community of practice. The case study contributes to the literature on the relation between information technology, organization and energy efficiency by investigating the socially situated nature of technology implementation and work practice change. The findings' implications for the role of information technology in improving energy efficiency in shipping are discussed.
\end{abstract}

Keywords Energy efficiency · Maritime operation · Energy monitoring · Information systems $\cdot$ Communities of practice Technology-in-practice

\section{Introduction}

The environmental impact attributed to shipping is significant. Emitting over 940 million tons of $\mathrm{CO}_{2}$ every year, maritime transport accounts for around $2.5 \%$ of the total annual anthropogenic greenhouse gas (GHG) emissions. The large techno-economical potential for improving energy efficiency in shipping has been demonstrated in several research studies (Bouman et al. 2017). The discrepancy, often called the energy efficiency gap, between the actual and potential level of energy efficiency, has been conceptualized and explained in terms of a number of different barriers within the behavioral, organizational and institutional levels of the shipping sector (Acciaro et al. 2013; Dewan et al. 2018; Johnson and Andersson 2014; Rehmatulla and Smith 2015). One of the allegedly most detrimental barriers is the lack of valid and reliable information on energy consumption. Consequentially, information on the potential improvements in energy efficiency related to the various available technical and operational measures is often not available (Jafarzadeh

Martin Viktorelius

martin.viktorelius@chalmers.se

1 Division of Maritime Studies, Department of Mechanics and Maritime Sciences, Chalmers University of Technology, Hörselgången 4, 41296 Gothenburg, Sweden and Utne 2014; Poulsen and Johnson 2016). This, in turn, has been demonstrated to be partly affected by shortcomings in energy management including insufficient practices and technologies related to energy performance monitoring (Armstrong and Banks 2015; Johnson et al. 2014).

The need for better energy management and energy monitoring has been recognized by the International Maritime Organization (IMO). It is now mandatory for shipping companies to implement energy management and establish monitoring practices on all ships "to evaluate the effectiveness of the planned measures", "deepen the understanding on the overall characteristics of the ship's operation" and "comprehend the trend of the efficiency improvement" (IMO 2016, p. 7).

However, energy-monitoring systems, arguably necessary for effective energy management, are still rare in shipping companies. Many still collect data on energy consumption manually, with the standard practice being that chief officers in navigation or engine departments send in consumption reports to the shore organization once a day but rarely get any feedback from shore. This has been reported to lead to a lack of transparency, data misreporting and lack of trust and support of energy consumption-monitoring policies, resulting in insufficient awareness and engagement on part of the crews (Poulsen and Johnson 2016; Poulsen and SornnFriese 2015). Moreover, the lack of auto-logging systems, 
collection of real-time data, and the non-use of computer applications, allowing statistical analysis of energy consumption and other relevant parameters, "prevents decision makers at sea and onshore from making adequate and prompt changes in ship operations to save fuel" (Poulsen and Johnson 2016, p. 3792). To enhance energy efficiency in ship operations, information on the energy consumed during different operational phases (cargo loading, maneuvering, navigation) needs thus to be made widely available for managers on shore and crew members at sea (Lützen et al. 2017). It has been argued that more information will enable increased awareness, better decisions and planning which will consequentially "allow onshore fleet managers and crews to immediately identify and realize cost-effective fuel saving initiatives [...] and adjust behaviour accordingly" (Poulsen and Johnson 2016, p. 3790). One reason making the dearth of information a particularly challenging problem is the complexity of ship energy consumption. Ships have numerous energy consumers (for propulsion, accommodation, cargo handling), they operate under highly variable conditions (weather, sea, routes, maintenance and loading) and they differ fundamentally in terms of design (size, speed, complexity and type of cargoes carried). Numerous factors thus influence the fuel consumption of a ship, which often varies significantly during and between voyages. This complexity, including the lack of knowledge on the ship and route specificity of energy consumption, makes it particularly difficult for crews to learn and develop optimal work practices (Rasmussen et al. 2018; Viktorelius and Lundh 2019). Implementation and use of information technology to monitor energy use is thus critical for efficient operations.

However, as pointed out by Jafarzadeh and Utne (2014, p. 611), a "common misconception" is that "the mere installation of equipment saves fuel". This view is aligned with a wide-spread idea in the energy research literature, often referred to as the information deficit model, according to which seemingly irrational behavior (not saving energy) can be explained by the lack of adequate information on energy consumption. It builds, however, on the criticized assumption that simply having access to more valid and reliable information will reduce energy consumption (Hargreaves 2018; Moezzi and Janda 2014; Owens and Driffill 2008). While equipment, such as measurement instruments may be installed onboard ships, there is no guarantee that they become utilized or effective in changing practices, which is essentially contingent on the adoption process within shipping companies. The affordances of any information system in facilitating improved energy practices in shipping can be argued to depend on both the materiality of technology (allowing real-time energy consumption measurement), and the social system of work and interaction. However, while the literature of energy monitoring and feedback in organization and work has focused on demonstrating the effect of monitoring on energy consumption behavior (Carrico and Riemer 2011; Dixon et al. 2015; Murtagh et al. 2013), few studies have addressed the social process of implementation and use of monitoring technologies. Kitada and Olcer (2015) suggest, for instance, that since policies and procedures are normally introduced from a shore-based office and then enforced on ships, it is important to investigate how ship crews adopt energy management technologies in their routines of work. They further note that since "it is commonly acknowledged that onboard crew tends to experience a gap in their perceptions of routine work on board when the shore-based managers try to enforce new policies and procedures into the ship" (Kitada and Olcer 2015, p. 38), it is particularly important to investigate how the visions and strategies of energy monitoring are shared, communicated, and promoted amongst ship crew members.

In this paper, these research gaps, regarding the organizational process of implementing information systems designed for facilitating energy monitoring in shipping, are addressed. Two research questions guided the study reported in this paper:

How are energy monitoring technologies adopted by crew members?

How can energy monitoring technologies improve the capacity to make better operational decisions during maneuvering and navigation?

The interpretative case study reported in this paper used a qualitative methodology to investigate how an energy-monitoring system installed onboard the ships in a shipping company was enacted as a legitimate artefact in the community of practice of the crew members through a process of situated learning, negotiation of meaning and mutual engagement (cf. Wenger 1998). As a result of this community and work-based adoption of the monitoring system, the company managed to reduce its annual fuel consumption with $20 \%$, representing the 'same amount of fuel it would require to propel one of their ships 2.5 laps around the globe'. This paper draws on the practice-based literature (Corradi et al. 2010; Nicolini 2012) to investigate and conceptualize the adoption and use of energy-monitoring systems in the shipping company.

\section{Theoretical background}

Research on the relation between information technology and organizational change has shown that the capacity of information technology to change routines and work practices is dependent on practitioners' situated actions (Orlikowski 1996) and social construction of the technology (Leonardi and Barley 2010). In the research field called workplace studies (Heath et al. 2000; Heath and Luff 2000; Luff et al. 2000), numerous studies have illustrated how 
technologies are constituted through and inseparable from the specifically situated practices of their use (Suchman et al. 1999). This has primarily meant that the traditionally supported idea that "the technical and social world operate according to rules that are prior to any particular situation" (Jackson et al. 2002, p. 239) and that technologies predict and determine organizational structure, is now out of fashion (Nicolini 2006; Orlikowski and Scott 2008). There is instead a widespread recognition that the success of technologies in improving work, and, e.g., making organizations more efficient, depends "on the extent to which they [technologies] resonate with their local contexts of use" and "in making technologies 'at home' in their very practical worlds of work" (Hindmarsh et al. 2007, 5).

The thesis that technology-induced organizational change is an effect of social construction, that "emerges from an ongoing stream of social action in which people respond to a technology's constraints and affordances" (Leonardi and Barley 2010, p. 1), has been prominently expressed in the research stream known as the practice-based approach (Barley 1986; Boudreau and Robey 2005; Chu and Robey 2008; Gherardi 2010; Orlikowski 1992; Rivera and Cox 2014; Vaast and Walsham 2005). From this perspective human agency (rather than institutional structures or technological features) is given a prominent role in explaining social order (Leonardi 2011).

Most studies taking a practice approach to technology base their theoretical framework on the work of Wanda Orlikowski (2000). From the perspective developed by Orlikowski (2000) social and organization structures (e.g., rules and resources guiding the management of energy) are not embodied in technology, neither are they determined by managerial imperatives or policies, but emerge from being enacted in practice by the people performing their work in everyday situations (Brown and Duguid 1991; Orr 1996). Technologies are not attributed any generally predictable consequences independently from the social context in which they are adopted and used (Feldman and Orlikowski 2011). While technological artefacts are designed with certain symbolic and material features affording certain uses, they are still open-ended before (and after) they are instantiated in activity, i.e., before they become technologies-in-practice: institutionalized and embodied ways of using technologies and organizing work in specific contexts (Orlikowski 2000). From this perspective, it follows that whether any energy-monitoring system enables and facilitates energy management in a company and contributes to it becoming sustainable, essentially depends on how it is enacted in practice.

Although the practice perspective has made a significant contribution to our theoretical understanding of the social nature of technology and the role it plays in constituting practice, few empirical studies have explored how technologies become enrolled in practice. Barley (1986) showed how the introduction of identical CT scanners in two radiology departments resulted in divergent forms of organization. Orlikowski (2000) illustrated how a particular system was enacted differently in different sites and organizations by the technicians and consultants using the system. Chu and Robey (2008) investigated why the enactment of an e-learning technology declined over time. However, less attention has been directed at how technologies become part of the enacted structures guiding action in the first place. And more importantly, why are new technologies often rejected by practitioners? A hint to the answer can be found in a paragraph by Orlikowski:

A community of users engaged in similar work practices typically enacts similar technologies-in-practice, where through common training sessions, shared socialization, comparable on-the-job experiences, and mutual coordination and storytelling, users come to engage with a technology in similar ways. Over time, through repeated reinforcement by the community of users, such technologies-in-practice may become reified and institutionalized, at which point they become treated as predetermined and firm prescriptions for social action, and as such, may impede change (2000, p. 411).

It is argued in this paper that the emphasis on communities of practice, and its related concept of negotiation of meaning and learning is key in understanding how technologies become adopted in practice, or why they are not. The next section reviews the notion of communities of practice (Lave and Wenger 1991; Wenger 1998) and indicates its relevance for understanding the emergence of energy-monitoring systems as technologies-in-practice.

\subsection{Enacting new technologies in communities of practice}

Work practice do not exist in the abstract but tend to develop within particular communities of professionals, such as those of claim processors' (Wenger 1998) or ship officers' (Hutchins 1995). It is within communities of practice that practitioners "organize their work with their colleagues" to "get the job done" and "fulfil the requirements of their employers and clients" (Wenger 1998, p. 6). Practices are, according to Wenger, first and foremost a process "by which we experience the world and our engagement with it as meaningful" (Wenger 1998, p. 51). The process, described as a negotiation of meaning, is conceived to involve both participation (meaningful social interaction in some activity) and reification (production and use of objects manifesting, or giving form to, those experiences of meaningfulness). 
Technologies-in-practice, being examples of both the process and outcome of a negotiation of meaning in communities of practice, can thus be seen as involving both reification and participation. They are enactments that emerge through participation and, at the same time, concrete "points of focus around which the negotiation of meaning becomes organized" (Wenger 1998, p. 58). Some attempts at reification do not originate in communities of practice, as is often the case when a company decides to implement a new technology in a work setting. However, to become meaningful parts of a practice (forms of reification and participation), technologies have to be re-appropriated into the local communities of practice. To understand adoption and use of new technologies it is, therefore, necessary to look closer at the constitution of communities of practice.

Communities of practice are held together by mutual engagement where members negotiate the meaning of their actions. Through this collective process of negotiation and interaction, a sense of a joint enterprise is created. Although every work practice is situated in a broader organizational and institutional context, with its particular requirements, constraints and resources, communities of practice are not determined by these conditions but respond to them and thus define the enterprise. The impact of an external force, such as the decision of a manager or the implementation of a new technology is thus always mediated by the community's own production of practice (Orr 1996). Rather than only being controlled from the outside, communities of practice have their own mechanisms for internal discipline. The negotiation of a joint enterprise gives rise to norms of mutual accountability among the participants including a sense of "what matters and what does not, what is important and why it is important, what to do and not to do, what to pay attention to and what to ignore[...] when action and artefacts are good enough and when they need improvement or refinement" (Wenger 1998, p. 81). Another source of coherence in communities of practice is the development of a shared repertoire, consisting of the activities, routines, ways of doing things, symbols, technologies and artefacts which have become a part of the practice. Established communities of practice may be difficult to change precisely because they constitute regimes of competence, tool-use and interaction. Technologies-in-practice are, therefore, structures that may be hard to break down or change.

Communities of practice form boundaries and discontinuities between those that have been participating in the community's shared histories and those that have not. Becoming a legitimate member and a fully participating insider of an established community of practice takes time and is often a slow and gradual process (Lave and Wenger 1991). To be contributing to the actual development of practice and the enactment of technology, the person needs to be (at least a partial) member of the community, i.e., participating in its everyday reproduction. Outsiders often have a hard time influencing the direction of a practice, and peripheral members are seldom allowed to significantly influence or change the practice. Consequentially, practices change primarily from the inside. Boundaries not only affect humans, they can also block artefacts from entering a practice as well if they are not perceived as legitimate elements of the joint enterprise and shared repertoire. Adoption of new technology has thus to be sanctioned by the core members of a community of practice.

Moreover, the development of practice and the enactment of new technologies-in-practice (adoption of new technology) are inextricably connected to learning (Boudreau and Robey 2005). From Lave and Wenger's socio-cultural perspective, learning is seen as a fundamentally situated process, a collective negotiation of meaning and an interplay between the established regimes of competence and new experience. Learning is thus not seen as a purely cognitive act, a "transmission of explicit, abstract knowledge from the head of someone who knows to the head of someone who does not" (Brown and Duguid 1991, p. 47). Instead, learning is a process in which practitioners may renegotiate the meaning of old or new technology in their practice by engagement and participation, tuning the definition of their enterprise or expanding their collective repertoire. Adopting new technologies and changing practices requires renegotiating the meaning of the joint enterprise and shared repertoire through mutual engagement and interaction.

It is suggested here that for new technologies, such as energy-monitoring systems, to become adopted by practitioners in a particular community of practice the artefact has to be enacted as a legitimate and meaningful element in the joint enterprise and shared repertoire. Adopting new technologies is a dual process of reification and participation: it involves rendering (reifying) the symbolic and material properties into meaningful elements in the joint enterprise and shared repertoire in the community of practice. It is suggested that this expansion of practice involves situated learning in which the meaning of the technology (its symbol and material properties) and the experience of using it is negotiated through a social process of mutual engagement among the practitioners within communities of practice.

\section{Research setting and methods}

This article draws upon a field study conducted in a Swedish shipping company owned by a larger international corporation within the transportation industry focusing on public transport. The shipping company owns 16 vessels and charters two, with an individual ship capacity of around 200-400 passengers. The shipping company uses the ships to provide their service for a local transportation company 
owned by the regional municipality responsible for delivering public transportation to the citizens. The service delivered is primarily to transport passengers between several islands within an archipelago and the city located on the mainland. The company was purposely chosen for the case study because it was known for having reduced its fuel consumption by $20 \%$ as a result of installing a fuel-monitoring system onboard its ships and had thus demonstrated that significant improvements in operational energy efficiency could be made without large investments. The organizational process that the company, and in particular the officers working on the ships, had experienced was, therefore, considered to be a valuable case to study to better understand how energy-monitoring information systems are adopted by crew members and how they may enhance the everyday operational practices in shipping.

Data collection was based on semi-structured interviews with 12 bridge officers working on 6 different ships, supplemented by observation of work carried out by the officers (maneuvering, navigation, maintenance). The interviews and observations took place between February and April 2018. The interviewees were encouraged to retrospectively elaborate on the events that took place during the implementation process of the monitoring system 2 years before the study as well as on the current use of it. This was done to be able to capture and interpret the temporally meaningful narrated episodes of the introduction of the system and the broader issue of energy saving related to their work (Flick 2000; Moezzi et al. 2017). The interviews onboard the ships often lasted several hours (on average $3 \mathrm{~h}$ ) as they were entangled with the observations during the voyages. The observations focused on how the system was used in practice and on the methods of saving energy during ordinary work that had been developed as a result of using the system. In addition to the observations and the interviews with the officers onboard the ships, one semi-structured interview was also held with a representative of the shore organization: the environmental manager. The manager had been responsible for introducing the system onboard and had appeared in public (conferences and media) speaking about the company and its environmental work. The researcher also attended a full day workshop that the company held with their employees covering topics related to sustainability and eco-shipping.

The recorded and later transcribed interviews and fieldwork notes were analyzed using a theoretically inspired thematic analysis to find repeated patterns or themes across the dataset pertaining to the research questions (Braun and Clarke 2006). Although the analysis was theoretically driven (by the practice-based approach to information systems), rather than purely inductive, the analytical process was recursive in the sense that the practice-theoretical framework used for analysis was continually re-fitted to the themes emerging in the progressively coded data until a stable conceptual mapping was achieved between the theoretical and empirical parts of the study (Dubois and Gadde 2002). In the final step of writing up the analysis, the themes were re-embedded into an analytical narrative of how the energy-monitoring system was implemented in the shipping company.

\subsection{Introducing the energy-monitoring system into the ship officers' communities of practice}

In 2010, the shipping company in this study decided to initiate a project to increase the operational energy efficiency in the fleet. This initiative was part of a larger effort of 'taking their responsibility' and becoming a more sustainable company, where eco-shipping and eco-driving, in particular, was considered to play a crucial part. Convinced that a substantial portion of the fuel consumption in the company was directly influenced by how officers performed their work and by "psychological factors", or what "is in the head of ship officers", the environmental manger wanted to find a tool with which to facilitate officers' awareness about energy in everyday work. A decision was made to invest money in a digital 'energy monitoring system' (EMS) that could be used both onboard by officers and on shore by managers to monitor and analyze fuel consumption. The argument for the investment was that if the energy consumption associated with the work practices could be more clearly visible then an automatic reduction in energy use would follow. Before the implementation of the EMS, fuel consumption was analyzed once a month by managers on shore and ship officers only got the feedback on how much had been consumed on occasional meetings a couple of times every year or presented in reports few had time to read. The invisibility of the consumption of energy made it difficult, for both managers and officers, to detect any patterns or relations between particular operational practices and energy consumption. Consequently, any improvement or change in work practices was difficult to achieve with such sporadic feedback. As expressed by the environmental manager:

Before the system we could only guess the reasons for differences in fuel consumption, we needed a system to track and analyze the causes. You cannot change your behavior if you get the feedback a month too late. It needs to be real-time and it's the person doing the work that needs the direct stimuli (Environmental manager).

The company purchased a system, described by its designers as "the ultimate tool on board for the crew to reduce and take control of the ship's energy consumption in real time", and installed it on two of their ships. The system consisted of two interconnected subsystems; one online analysis tool and one onboard real-time monitoring display. The online tool could be used for following up and analyzing 
fuel consumption of individual ships or the whole fleet. Centralized internet servers continuously recorded information about fuel consumption, position, speed and several other parameters. The collected data could be selected and re-presented in many different ways: statistical functions could, for instance, be used to generate graphs presenting different vessel parameters at specific time frames while also showing the geographical location of the vessels at a particular point in time; different routes or different trips on the same route could be compared; a 'correlation report' presenting a graph that showed the correlation between multiple parameters such as speed over ground and litres per nautical miles could also be generated. This subsystem was mainly to be used on shore but could in principle also be utilized by officers on the ships if they used a computer with internet access (see Fig. 1 for an example of the interface of the online analysis tool). The other subsystem was an onboard tool particularly customized for officers to be used during ship operations. It integrated various onboard systems and flowmeters to monitor fuel and energy consumption and other parameters in real time. The main view on the onboard display showed how many litres or kilograms were consumed per hour or nautical miles, it also presented the average of these real-time measurements (Fig. 2). Another window displayed an automatically built up fuel profile, similar to that in the systems' analysis module, showing the vessel's fuel consumption at different speeds.

The system was installed on two bridges, to start with, so that officers could access the real-time measurements during their work. Now officers could see, in detail, what they consumed and could analyze their practices with the help of advanced information technology and statistical tools. The system had been marketed as easy to use with a simple user interface. The managers hoped that the system would result in officers becoming more aware of the fuel consumption and thereby reduce it. However, to the surprise

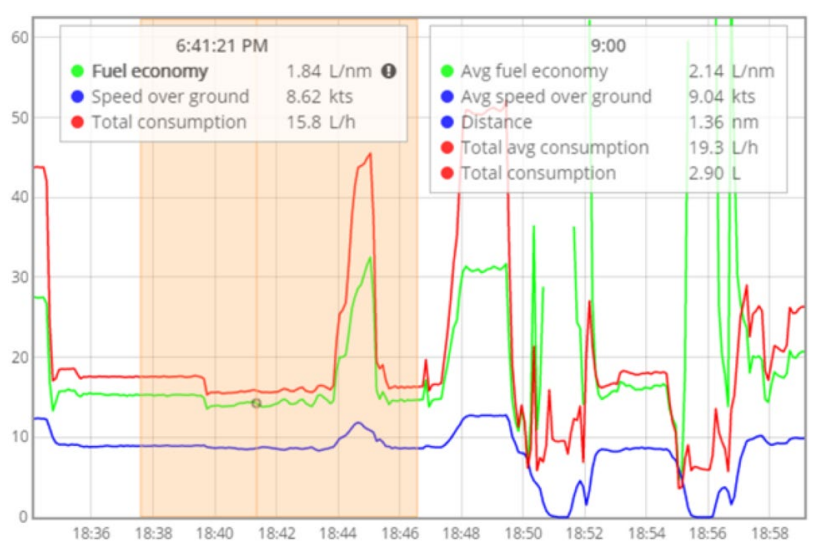

Fig. 1 Interface of the online analysis tool

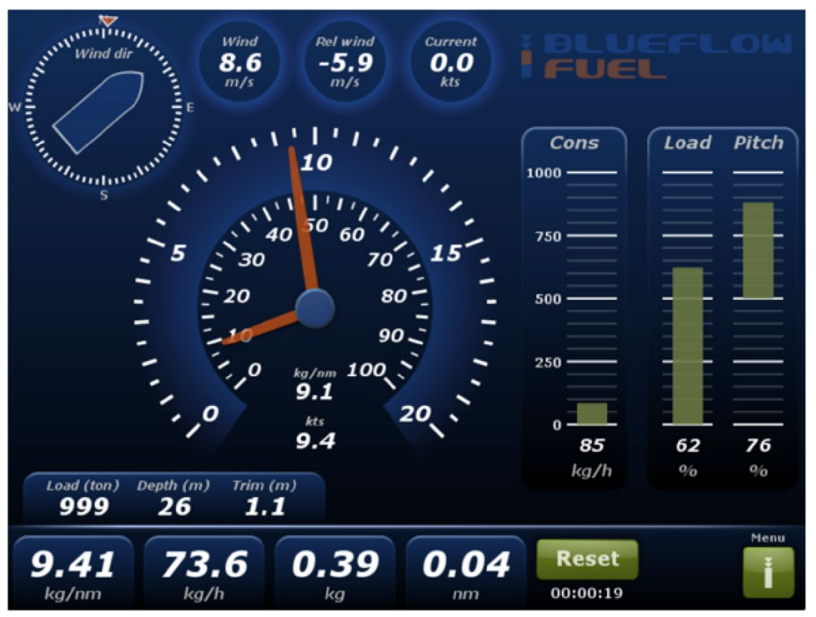

Fig. 2 Interface of the onboard monitoring energy system

and disappointment of the managers, they soon discovered that the ships did not reduce their consumption as expected.

\section{Professional autonomy, identity and boundaries between ship and shore communities}

The initial reaction of the officers when the system was installed was to continue as usual and not to take a lot of notice of the system. The current practices had obviously worked so far (the ships were on time and passengers were happy) so why change them now? Some, however, also expressed more explicitly negative attitudes towards the system as recalled by an officer:

There were many that did not like this at all. Frankly, they did not give a [sh*t] about the system. Refused to use it, declaring that they will do it exactly as they always have done it (Deck officer).

The sense of autonomy was strong and highly valued in the community of practice onboard the ships. Historically, deck officers had always been responsible for many operational decisions. The nature of ship operations, being a safety critical enterprise where difficult situations requiring fast and apt decisions often arise, had rewarded self-sufficiency, autonomous professional judgements and competence within the onboard community to handle every situation in a safe manner. Suggestions or directions from managers and other shore-based personnel that lacked ship experience were thus perceived with skepticism and rejected on the grounds of not being based in the realities of seafaring.

The environmental manager, who was responsible for the implementation of the system explained that a frequent sarcastic comment she got from officers in the beginning of 
the project was: "So are you trying to teach me how to drive my ship?" The boundary between the 'onboard' community of practice and the perceived 'other', i.e., 'the shore-based manager', thus created difficulties in influencing and shaping the operational practices for an outsider like the manager, given her non-participation in the onboard community.

Moreover, some officers saw the system as a surveillance tool and did not want to be 'watched' or 'monitored' which they interpreted as disempowering them. Many were also generally skeptical towards new instruments to be used based on the argument that they already had all the equipment necessary to perform their work competently. However, the most essential of the initial difficulties of the energysaving ambition of the company was, according to the environmental manager, that many officers were convinced that they already did everything they could to consume as little fuel as possible and that the primary factors influencing consumption were located outside the control of the officers themselves.

The system was thus first interpreted as an unnecessary and provocative device implying that officers did not already perform their work in an optimal way and that there existed room for improvement in spite of many years of experience. This perceived implication was particularly offensive for older and more senior officers who had worked as seafarers their whole adult lives and considered themselves to be professionals with sufficient knowledge to handle a ship in an optimal way. The challenge of implementing the system in practice to change the way officers performed their work, was thus not only that of making officers process some facts or figures about energy consumption but also involved professional identity, sense of autonomy, understanding and embodied know-how as developed in the community of practice.

The environmental manager believed that although the system was optimal for the task of monitoring energy consumption (seen from a material perspective the system afforded all the actions required for energy performance monitoring) the more important challenge was to integrate the system and appropriate its features and functions in practice:

Now we have the best system in the world, but how should we work with it? (Environmental manager).

This experience of the initially failed attempt at implementing the system forced the environmental manager to re-think her approach which she acknowledged had been too naïve. She expressed, somewhat self-ironically, that the initial strategy related to the implementation of the system had been based on a type of reasoning similar to the questionable belief that "if you just buy a bathroom scale with larger display you will automatically reduce your weight". This initially adopted deterministic view of how technology changes organizational practices and skills was difficult to hold on to in light of the apparent inertia and absent use of the installed system. The environmental manager explained her insight by continuing the metaphor used previously:

If you are in denial you will not realize that you need to lose weight even if you have a bathroom scale (Environmental manager).

The big question thus became how they could "make people accept the system and understand that they could make a difference only if they tried saving energy". Given the strong community of practice onboard the ships, the environmental manager realized that her ambition of changing navigational practices to improve energy efficiency and implement energy-monitoring practices could not be perceived as 'requirements' coming from a manager on shore. She thought that change would be more likely if the officers made themselves realize how to optimize their own practices rather than receiving instructions from shore. Being an environmental manger, she did not think she had the power and respect to encourage individual officers to navigate and maneuver in new ways that differed from the practices that had been developed from years of experience. However, if the suggestions came from a colleague onboard, she reasoned, they might be perceived as more legitimate and acceptable:

If I've said that the most optimal operational profile looks like this or that we would not have saved a single litre, but if the officers themselves could be made to see that for instance taking a slightly different route saves this much then it is possible to save a lot (Environmental manager).

\subsection{New implementation strategy: enrolling members from within the community of practice}

The need to find a way of legitimizing the use of the system, together with the apparently impervious community onboard, prompted the idea of gathering a small group with interested representatives from the ships that could be enrolled into the implementation project and act as advocates for the system, "from the inside". This was thought to enable an opening in the boundary between the community of navigational officers and the new system advocated by the shore office. The system was installed on two more ships and a project group was created with one officer from each of the four ships now equipped with the system. The task of the group was to find a way to address the skepticism and reluctance to use the system and convince colleagues about the value of the technology and the possibility to create shared practices. The group started to have regular meetings and 
discuss the system and how it could be practically applied. This resulted in a re-negotiation of old assumptions and taken for granted beliefs about fuel consumption that were seldom questioned by themselves and their colleagues. They made use of the monitoring system and scrutinized the accumulated data and looked for trends to find some empirical ground for what and how work practices could be improved.

One such deeply ingrained assumption had for instance been that the only way of reducing the energy consumption was to reduce the average speed of the ships. The only way of doing this was to change the time table of the ships to introduce more slack in the schedule. This presumed fact was used by many officers as an argument that they could not do anything to improve the efficiency since the decision to change the time table essentially rested in the hands of the operational managers. The group of selected officers was soon able to demonstrate, using data from the system, that this was not necessarily the case. They saw that ships that operated with a generally higher average speed were not necessarily the ones that consumed the most fuel and the ships with the lowest average speed did not have the lowest fuel consumption. Instead, what seemed to play a more important role for fuel consumption was the manner in which maneuvers were performed. To reify this insight, the group was able to produce statistical graphs that compared two anonymized officers operating the same ship under similar weather conditions on different occasions. The graph showed that although the average speed and distance sailed was the same for the two officers, one had consumed $92.4 \mathrm{~L}$ while the other had consumed $62.9 \mathrm{~L}$, in total.

The mutual engagement and interaction between the officers in the project group created trust in the system and showed that energy could be saved by improving the maneuvers without compromising with the punctuality of the voyages. Based on a number of different analyses and findings, the group identified several operational measures that could be applied onboard the ships to improve energy efficiency. These included slow accelerations, utilization of bow thrusters, reducing speed earlier before berthing, avoid ship squatting in shallow waters, utilize sea currents, and reduce engine use at berth.

The re-negotiation of the meaning of the EMS and their own shared repertoire of assumptions, beliefs and practices enabled the officers in the project group to establish a legitimate role for the system in the process of improving their operational procedures. The system assisted the group to construct and reify an argument for the value of the technology and an appealing proof of the potential for improvement that could now be used in the dialog with the rest of the crew to illustrate "the impact that the driving style can have on the fuel consumption". However, the growing participation and reification in relation to the system was still bounded to the small project group. The challenge was still how to translate it into the definition of the joint enterprise and shared repertoire of the whole community of practice within the company.

\subsection{Renegotiating the meaning of technology through mutual engagement and learning}

The group compiled their conclusions from their work in a document but decided to also use a more pragmatic face-toface and personal approach in bringing it to their colleagues and initiated a series of training sessions where officers on each of the ships, together with representatives from the project group (acting as boundary spanners between the ship and shore communities), could explore the possibilities of the EMS and learn from that collective effort during actual operation.

The training sessions were improvised each time but were generally arranged in the following fashion for each of the officers on the different ships: one of the officers from the project group (called moderator below) asked if he could come onboard to discuss the system with his colleague and illustrate how he used it and demonstrate what the project group had discovered could be improved. The officer on the ship was then first asked to maneuver and navigate as he always does without thinking about saving energy or the measurements shown on the system display. After approximately an hour of driving the officer was asked to do the same trip but this time try to apply some of the suggestions derived from the discussion in the group or something else the officer on the ship suspected could reduce the fuel consumption. Then they logged into the system's analytical program accessible via a PC with internet connection and compared the fuel consumption by marking the ship, geographical area and time duration in which the test had been performed to select the data relevant for comparison.

We tried different things and then went to the computer to see the difference. We marked the voyages we wanted to compare and could see, with deciliter accuracy, the difference (Deck officer).

After each session (which was repeated two times) officers were requested to write a log on which measures had been tried and which would be tested the next session. The process of discussion and testing was similar to that which the project group had done and did indeed reveal many assumptions and habits that officers had and that could be questioned based on the data. Through this method officers could see directly how large or small the difference was in energy efficiency between the normal and test voyages. One of the officers from the project group explained that "very often we could see a difference of $20 \%$ and in one extreme case one officer improved by $40 \%$ ". 
One of the moderators from the project group who had done most of the ship visits was initially a bit worried about the reactions from his colleagues by this unfamiliar way of collaboration (normally officers did not explicitly comment on each other's work) and did not want to be interpreted as a self-appointed 'expert' that came onboard to tell others how to do it right. Consequently, the moderator was keen to enact a role which he identified more as an equal discussion partner trying to figure something out together with his colleague, rather than that of an instructor or teacher.

It was quite sensitive to me when I was around on the various boats. Met people with twice as much experience as I have. You had to be very humble and careful and say that I do not think I have the most correct way to do it but that my way has worked so I would like to introduce it to you. And at the same time learn from someone that has worked with this a long time. Not 'now I will teach you' but rather 'let's discuss it together'. They often had things to say to me that I could think about. It never became a requirement, but everyone did what they felt they had the capacity to do (Deck officer/moderator).

The moderator considered it important not to give the impression of blaming colleagues but to create a positive feeling surrounding the possibility for improvement by demonstrating the potential in their own work. He told his colleagues that the system was an experimental tool with no requirements attached and that not all suggestions from the project group had to be adopted. The purpose was to explore the possibilities for improvement and reflect on their own practices, with the help of the system, rather than to enforce a particular procedure of how to use the system or how to navigate and maneuver more energy efficiently.

At the same time, the moderator had, as a member of the project group appointed by the environmental manager, a dual role as a broker between the community of the 'shoremanagers' and officers, rather than being a pure participant in the normal interaction between crew members. However, his full membership in the onboard community allowed him to successfully participate in the negotiation of the meaning of the system and its application. This strategy evidently succeeded since officers did not interpret the content of the training as coming from shore but as developed by colleagues.

We got no direct orders. Instead the whole project was based on discussions between us where we shared experiences (Deck officer).

We were encouraged to find ways to save energy instead of receiving directions (Deck officer).
Once officers could see the difference in fuel consumption during the peer-learning session they became much more positive to the system. However, participation and mutual engagement in communities of practice does not mean total agreement or consensus (Wenger 1998). Although no one criticized or opposed the peer-learning sessions per se, not everyone enthusiastically embraced all suggestions. A crucial element in the training sessions was negotiating the meaning of the different operational measures and what they entailed or required in terms of effort and workload. Officers could, for instance, discuss whether a particular measure, or how often it was applied, was worth the mental concentration it required if it only saved a couple of decilitres of fuel per hour.

When you have been on your shift for many hours you don't have the mental focus to make the perfect acceleration or the perfect maneuver all the time (Deck officer).

Nevertheless, soon even the initial skeptics were convinced about the value of both the system and the possibility to improve the energy efficiency. As the interest grew and more officers had been convinced that opportunities for improvement did in fact exist it became harder to ignore the system. Officers explained that they did not want to appear as less competent than their colleagues or as if they did not have control over their own driving. Hence, a new norm of mutual accountability had been developed. As expressed by one officer:

I think many felt that if my colleague is interested in this then I don't want to be left outside, and also that you could actually see the consumption of your colleague when you start a new shift. You don't want to be worse than your next mate (Deck officer).

Officers believed that the changes were a direct consequence of the peer-learning session where particular techniques and routines were discussed and analyzed. Some of the modifications in practice had been based on the suggestions that the moderators and the project group had identified before the peer-learning sessions but most measures had been identified in the sessions by reasoning, analyzing and discussing things together and thus often included measures that had not been identified prior to the session by the group.

\subsection{The effects: modifications in work practice}

In 2017, the company had installed the system on all its ships and most officers had done the peer-learning. At that time, the company was annually saving between 20 and $25 \%$ fuel, compared to before the installation of the system and the peerlearning. All interviewed officers believed that the system and the peer learning had contributed to this improvement. All 
officers interviewed claimed that they had made modifications to their practices and changed many of their navigational routines and maneuvering techniques. As expressed by two officers:

I have developed a whole new way of navigating. It's much more soft and calm" not as aggressive, you plan the maneuvers and berthing better now, instead of using everything [power available] no matter how the wind is I can now take the wind more into account earlier in my plan so I don't have to use excessive force right before the wharf for example (Deck officer).

Before the system and the discussions we had, I always took that way around that island [officer pointing] but after the tests we could see that we could save a couple of litres by taking another route although it was longer in distance. I always take the cheaper way now but I never did it before the tests we did. Thanks to the tests I always think about the differences we found by evaluating the routes. It has affected me (Deck officer).

However, during the observations on the bridges it was also evident that few officers did actually use the system on a regular basis by integrating the real-time information from the system in their maneuvering and navigational activities. Although the training sessions had resulted in many lasting navigational changes, no sign of persistent monitoring practices allowing further improvements could be observed. This was also confirmed in the interviews were most officers thought that the system had been useful in the discussions but less so in ordinary work. Hence, outside the context of the peer-learning sessions, normal work took precedence. Moreover, many also believed that although the system had contributed to change the saliency of energy in the discourse among crew members, it was not the information per se that had enabled the change but rather the discussions and interactions that took place during the project.

In sum, the peer-learning enabled the (temporary) enactment of the system as a collaborative experimentation tool relevant for the work onboard rather than a management control tool. This enabled an interpretation of the system that was consistent with the officers' self-conception and identity as competent professionals. Instead of seeing it as a technology that curtailed the autonomy and self-governance of officers it was made into a technology that emphasized officers' autonomy, decision making and ability to analyze the functioning of complex technical systems.

\section{Discussion and conclusions}

The aim of this paper has been to contribute to the debate on energy efficiency and the need for better energymonitoring practices in shipping. It was argued that to understand the adoption and use of new technologies it is necessary to focus on the situated practices, relations and social meanings of the actors involved in particular implementation projects (Boudreau and Robey 2005; Chu and Robey 2008; Cousins and Robey 2005; Orlikowski 2000). To explore the performative (work-as-done), rather than the ostensive (work-as-imagined) definitions of technology adoption and use (Czarniawska 2014) it was necessary to conduct an interpretative case study, with a detailed contextual analysis and thick descriptions making the interpretations "available in the consultable records" (Walsham 1995).

Highlighting the research gap pertaining to how energymonitoring systems are implemented in shipping companies, this study addressed the role that communities of practice play in the social process of adopting information technology facilitating energy performance monitoring onboard ships. The concepts of negotiation of meaning and learning as developed in Wenger's (1998) theory on communities of practice offered an explanation of how the socially situated process of adopting the energy-monitoring system was mediated by officers' participation and reification vis-á-vis the system and its affordances.

\subsection{How are information technology (energy-monitoring systems) adopted by practitioners (ship officers)?}

The case study illustrates how the adoption of new technology in work practices is dependent on the enactment of a meaningful social context in which situated learning, involving both participation and reification, can take place, enabling an expansion and modification of the regime of competence and allowing new experiences and norms to enter the discourse. The mutual engagement and negotiation of meaning within the community of practice was seen to open up the conceptual and material space for new practices, skills and norms to be developed. The situated learning enabled by the experimentations and reflections on practice and the EMS during the training sessions allowed an opening for the new artefact to enter the shared repertoire of the community of practice.

Consequently, officers did change their practices as a result of the meaningful social context enacted in the project group and peer-learning sessions. Before this context was created, the system was not enacted as a 
technology-in-practice that made sense or fulfilled the perceived purpose of the work. The meaning of the system was first interpreted by the officers as a control tool diminishing their power, authority and autonomy, thus posing a threat to their professional identity as both competent and self-sufficient. The value of the system was thus not considered high and few believed that it had any potential for improving the ship operations. Since neither energy management nor energy monitoring formed a part of the traditionally defined joint enterprise and shared repertoire onboard the ships, the initial challenge of implementing the system involved expanding the community's conception of itself and its practices (as improvable). The initial efforts of implementation failed because it was not based in the social dynamic of the community of officers working onboard the ships. In particular, the traditional boundary between the ship and shore community did not allow a straightforward shore-based reconfiguration of the work practices onboard. The managerial attempt to manage energy-consuming behavior onboard by monitoring and control was met with resistance as a way of protesting against the transference of control from ship to shore. To maintain their autonomy (power) and identity, crew members could not let the definition of competence be given away to the management and certainly not to some inanimate technology. To reframe the use of the system, as a tool assisting in work, and as an expression of the competence of officers, it had to be re-enacted from within the onboard community of practice as a legitimate element in the officers' joint enterprise and shared repertoire. However, for this to happen, officers had to engage in a process of situated learning where the meaning of the EMS and their maneuvering and navigational practices was re-negotiated. The idea to gather a small group of officers and give them the authority to define the problem and explore the system was a first important step towards such a process. The group quickly felt a responsibility and interest in exploring the significance of the system and the possibilities for improvement. The experience and knowledge created in the group was later utilized in the subsequent enrolment of the rest of the crew. This required, however, further negotiations and interactions between officers where various alternative maneuvering and navigational choices were compared and evaluated. The training sessions functioned as a socially legitimate arena in which colleague officers could explore how much could be saved by different changes rather than just adopt the results from some analysis made onshore. Here, the project group, and in particular the two peer-training moderators, played an important role in legitimizing the system in the community. The use of the monitoring technology became legitimate (considered for inclusion in the shared repertoire) first when practitioners with full memberships in the community of practice started to engage colleagues and initiated a mutual negotiation about the system. The moderators' role as boundary spanners (Levina and Vaast 2005), crossing the boundary between the ship and shore community, made it possible for other officers to explore the system and become exposed to new experiences, thus expanding the current regime of competence in the community. The mutual engagement between the officers exploring the system in the individual sessions played a crucial role in envisioning what the system could become as a technology-in-practice (Orlikowski 2000).

The system, as enacted in the peer-training, made officers see the potential improvements in their own ways of navigating and maneuvering and were thus convinced to see the value of the new technology. When officers began to realize that other colleagues were saving energy, their felt lack of knowledge became a potential threat of no longer belonging, being a fully participating member, of the community. This, essentially motivated them to improve the energy efficiency of their work. The adoption process of the system thus included a number of reifications (statistical calculations, production of documents with operational measures, writing a log of areas of improvement) and participations (project group meetings and collaborations, peer-learning sessions). Both types of elements were used to negotiate the meaning of the system. The process by which the system got entangled with the social interactions of officers not only changed their attitudes and beliefs about the system, it also changed their embodied and situated work practices.

Based on the findings, it can be concluded that successful energy-monitoring practices in shipping involve, not only the introduction of auto-logging monitoring systems, plans and explicit goals, but also, and more importantly, participation and engagement on the part of the practitioners constituting the communities of practice on which the management of energy depends. The results also show that the implementation of technology and change in work practice requires a focus on the social context, meanings and interpretations guiding practitioners as they perform their everyday work.

\subsection{What role can EMS have in officers' work and how can EMS facilitate decision making?}

The case illustrates that rather than immediately contributing to officers' decision making, EMS can play a mediating role in a negotiation of practice, eventually leading to improved operations. The information deficit model, underlying most research on energy monitoring, is based on a rationalist understanding of decision making where the right sort and amount of information will lead to more optimal decisions (Hargreaves 2018). This study suggests that rather than having this role, EMS can be expected to have implications for practices, not primarily because of its informational 
properties but rather because of its social effects. This was illustrated by the finding that although the system did, eventually, have the desired effect of making energy consumption more salient in the work of the officers, consequentially improving practice, it was evident that the effect was contingent on the system being enacted as a relational mediator, allowing collective sense making of the information it generated. The system became a meaningful artefact in practice allowing an expansion of the regime of competence, as a result of the mutual engagement and interaction that was made possible through the creation of the project group and the peer-learning sessions. Outside of the temporary social context enacted in the training sessions, where a particular way of interacting with the system and colleagues emerged, the system was not used. This indicates that while an EMS can become a technology-in-practice in one social context, the informational affordances of the energy-monitoring system do not necessarily emerge in all sociomaterial configurations. It is, therefore, important to acknowledge that the potential of energy monitoring to reduce consumption does not only depend on the technical features (e.g., sub-metering, availability of valid and reliable data, interface design) of the systems acquired in companies, but also on the social processes implicated in the adoption and use of the technology.

The findings in this study contribute to the literature on energy monitoring and feedback in shipping (Poulsen and Johnson 2016; Poulsen and Sornn-Friese 2015) as well and other workplace and organizational settings (Carrico and Riemer 2011; Siero et al. 1996). While most of the latter studies aim at investigating the quantifiable effect of monitoring and feedback on energy conservation behavior (with highly varying results) they have been mute on how monitoring systems become technologies-in-practice and have, therefore, failed to offer a deeper understanding of how any effects or changes in practice may arise. By focusing on either the technical or the behavioral potential, most studies neglect what (Bull and Janda 2018; Moezzi and Janda 2014) call social potential, i.e., the situated and participatory process by which energy problems are defined and addressed. Similar to this notion, the energy efficiency potential in this case, as analyzed in the paper, was seen to be socially enacted; that is, it was neither embodied in the technology nor purely a matter of individual officers applying certain predefined measures, but rather a result of the participation and engagement among the practitioners (Orlikowski 2000).

Open Access This article is distributed under the terms of the Creative Commons Attribution 4.0 International License (http://creativeco mmons.org/licenses/by/4.0/), which permits unrestricted use, distribution, and reproduction in any medium, provided you give appropriate credit to the original author(s) and the source, provide a link to the Creative Commons license, and indicate if changes were made.

\section{References}

Acciaro M, Hoffmann PN, Eide MS (2013) The energy efficiency gap in maritime transport. J Shipp Ocean Eng 3:1-10

Armstrong VN, Banks C (2015) Integrated approach to vessel energy efficiency. Ocean Eng 110:39-48. https://doi.org/10.1016/j.ocean eng.2015.10.024

Barley SR (1986) Technology as an occasion for structuring-evidence from observations of ct scanners and the social-order of radiology departments. Adm Sci Q 31:78-108. https://doi. org/10.2307/2392767

Boudreau MC, Robey D (2005) Enacting integrated information technology: a human agency perspective. Organ Sci 16:3-18. https:// doi.org/10.1287/orsc. 1040.0103

Bouman EA, Lindstad E, Rialland AI, Stromman AH (2017) State-ofthe-art technologies, measures, and potential for reducing GHG emissions from shipping - a review. Transp Res Part D Transp Environ 52:408-421. https://doi.org/10.1016/j.trd.2017.03.022

Braun V, Clarke V (2006) Using thematic analysis in psychology. Qual Res Psychol 3:77-101. https://doi.org/10.1191/1478088706qp063 oa

Brown JS, Duguid P (1991) Organizational learning and communitiesof-practice: toward a unified view of working, learning, and innovation. Organ Sci 2:40-57. https://doi.org/10.1287/orsc.2.1.40

Bull R, Janda KB (2018) Beyond feedback: introducing the "engagement gap' in organizational energy management. Build Res Inf 46:300-315. https://doi.org/10.1080/09613218.2017.1366748

Carrico AR, Riemer M (2011) Motivating energy conservation in the workplace: an evaluation of the use of group-level feedback and peer education. J Environ Psychol 31:1-13. https://doi. org/10.1016/j.jenvp.2010.11.004

Chu TH, Robey D (2008) Explaining changes in learning and work practice following the adoption of online learning: a human agency perspective. Eur J Inf Syst 17:79-98. https://doi. org/10.1057/palgrave.ejis.3000731

Corradi G, Vendelø MT, Dehler GE, Christensen PH, Gherardi S, Verzelloni L (2010) Through the practice lens: where is the bandwagon of practice-based studies heading? Manag Learn 41:265283. https://doi.org/10.1177/1350507609356938

Cousins KC, Robey D (2005) Human agency in a wireless world: patterns of technology use in nomadic computing environments. Inf Organ 15:151-180

Czarniawska B (2014) A theory of organizing. Edward Elgar Publishing, Cheltenham

Dewan MH, Yaakob O, Suzana A (2018) Barriers for adoption of energy efficiency operational measures in shipping industry WMU. Marit Aff 17:169-193. https://doi.org/10.1007/s1343 7-018-0138-3

Dixon GN, Deline MB, McComas K, Chambliss L, Hoffmann M (2015) Using comparative feedback to influence workplace energy conservation: a case study of a University Campaign. Environ Behav 47:667-693. https://doi.org/10.1177/0013916513520417

Dubois A, Gadde LE (2002) Systematic combining: an abductive approach to case research. J Bus Res 55:553-560. https://doi. org/10.1016/S0148-2963(00)00195-8

Feldman MS, Orlikowski WJ (2011) Theorizing practice and practicing theory. Organ Sci 22:1240-1253. https://doi.org/10.1287/ orsc. 1100.0612

Flick U (2000) Episodic interviewing. In: Bauer M, Gaskell G (eds) Qualitative research with text, image and sound: a practical handbook. Sage, London, pp 75-92

Gherardi S (2010) Telemedicine: a practice-based approach to technology. Hum Relat 63:501-524. https://doi.org/10.1177/00187 26709339096 
Hargreaves T (2018) Beyond energy feedback. Build Res Inf 46:332342. https://doi.org/10.1080/09613218.2017.1356140

Heath C, Luff P (2000) Technology in action. Cambridge University Press, Cambridge

Heath C, Knoblauch H, Luff P (2000) Technology and social interaction: the emergence of 'workplace studies'. Br J Sociol 51:299320. https://doi.org/10.1080/00071310050030190

Hindmarsh J, Jenkings KN, Rapley T (2007) Introduction to healthcare technologies in practice. Sage Publications Sage, Thousand Oaks

Hutchins E (1995) Cognition in the wild. MIT Press, Cambridge

IMO (2016) Guidelines for the development of a ship energy efficiency management plan http://www.imo.org/en/OurWork/Environmen t/PollutionPrevention/AirPollution/Pages/Index-of-MEPC-Resol utions-and-Guidelines-related-to-MARPOL-Annex-VI.aspx. Accessed 4 Feb 2018

Jackson MH, Poole MS, Kuhn T (2002) The social construction of technology in studies of the workplace. In: Livingstone S, Lievrouw LA (eds) Handbook of new media: social shaping consequences of ICTs. Sage, London, pp 236-253

Jafarzadeh S, Utne IB (2014) A framework to bridge the energy efficiency gap in shipping. Energy 69:603-612. https://doi. org/10.1016/j.energy.2014.03.056

Johnson H, Andersson K (2014) Barriers to energy efficiency in shipping WMU. J Marit Aff 15:79-96. https://doi.org/10.1007/s1343 7-014-0071-z

Johnson H, Johansson M, Andersson K (2014) Barriers to improving energy efficiency in short sea shipping: an action research case study. J Clean Prod 66:317-327. https://doi.org/10.1016/j.jclep ro.2013.10.046

Kitada M, Olcer A (2015) Managing people and technology: the challenges in CSR and energy efficient shipping. Res Transp Bus Manag 17:36-40. https://doi.org/10.1016/j.rtbm.2015.10.002

Lave J, Wenger E (1991) Situated learning: legitimate peripheral participation, Cambridge University Press, Cambridge

Leonardi PM (2011) When flexible routines meet flexible technologies: affordance, constraint, and the imbrication of human and material agencies. MIS Q 35:147-167

Leonardi PM, Barley SR (2010) What's under construction here? Social action, materiality, and power in constructivist studies of technology and organizing. Acad Manag Ann 4:1-51

Levina N, Vaast E (2005) The emergence of boundary spanning competence in practice. Implications for implementation and use of information systems. MIS Q 29:335-363. https://doi. org $/ 10.2307 / 25148682$

Luff P, Hindmarsh J, Heath C (2000) Workplace studies: recovering work practice and informing system design. Cambridge University Press, Cambridge

Lützen M, Mikkelsen LL, Jensen S, Rasmussen HB (2017) Energy efficiency of working vessels—a framework. J Clean Prod 143:90-99. https://doi.org/10.1016/j.jclepro.2016.12.146

Moezzi M, Janda KB (2014) From "if only" to "social potential" in schemes to reduce building energy use. Energy Res Soc Sci 1:30 40. https://doi.org/10.1016/j.erss.2014.03.014

Moezzi M, Janda KB, Rotmann S (2017) Using stories, narratives, and storytelling in energy and climate change research. Energy Res Soc Sci 31:1-10. https://doi.org/10.1016/j.erss.2017.06.034

Murtagh N, Nati M, Headley WR, Gatersleben B, Gluhak A, Imran MA, Uzzell D (2013) Individual energy use and feedback in an office setting: a field trial. Energy Policy 62:717-728. https://doi. org/10.1016/j.enpol.2013.07.090

Nicolini D (2006) The work to make telemedicine work: a social and articulative view. Soc Sci Med 62:2754-2767. https://doi. org/10.1016/j.socscimed.2005.11.001
Nicolini D (2012) Practice theory, work, and organization: an introduction. OUP, Oxford

Orlikowski WJ (1992) The duality of technology—rethinking the concept of technology in organizations. Organ Sci 3:398-427. https ://doi.org/10.1287/orsc.3.3.398

Orlikowski WJ (1996) Improvising organizational transformation over time: a situated change perspective. Inf Syst Res 7:63-92. https:// doi.org/10.1287/isre.7.1.63

Orlikowski WJ (2000) Using technology and constituting structures: a practice lens for studying technology in organizations. Organ Sci 11:404-428. https://doi.org/10.1287/orsc.11.4.404.14600

Orlikowski WJ, Scott SV (2008) 10 Sociomateriality: challenging the separation of technology, work and organization. Acad Manag Ann 2:433-474. https://doi.org/10.1080/19416520802211644

Orr JE (1996) Talking about machines: an ethnography of a modern job. Cornell University Press, Ithaca

Owens S, Driffill L (2008) How to change attitudes and behaviours in the context of energy. Energy Policy 36:4412-4418. https://doi. org/10.1016/j.enpol.2008.09.031

Poulsen RT, Johnson H (2016) The logic of business vs. the logic of energy management practice: understanding the choices and effects of energy consumption monitoring systems in shipping companies. J Clean Prod 112:3785-3797. https://doi. org/10.1016/j.jclepro.2015.08.032

Poulsen RT, Sornn-Friese H (2015) Achieving energy efficient ship operations under third party management: how do ship management models influence energy efficiency? Res Transp Bus Manag 17:41-52. https://doi.org/10.1016/j.rtbm.2015.10.001

Rasmussen HB, Lutzen M, Jensen S (2018) Energy efficiency at sea: knowledge, communication, and situational awareness at offshore oil supply and wind turbine vessels. Energy Res Soc Sci 44:50-60. https://doi.org/10.1016/j.erss.2018.04.039

Rehmatulla N, Smith T (2015) Barriers to energy efficient and low carbon shipping. Ocean Eng 110:102-112. https://doi.org/10.1016/j. oceaneng.2015.09.030

Rivera G, Cox A (2014) An evaluation of the practice based approach to understanding the adoption and use of information systems. $\mathbf{J}$ Doc 70:878-901. https://doi.org/10.1108/Jd-06-2013-0080

Siero FW, Bakker AB, Dekker GB, vanden Burg MTC (1996) Changing organizational energy consumption behaviour through comparative feedback. J Environ Psychol 16:235-246. https://doi. org/10.1006/jevp.1996.0019

Suchman L, Blomberg J, Orr JE, Trigg R (1999) Reconstructing technologies as social practice. Am Behav Sci 43:392-408. https:// doi.org/10.1177/00027649921955335

Vaast E, Walsham G (2005) Representations and actions: the transformation of work practices with IT use. Inf Organ 15:65-89. https ://doi.org/10.1016/j.infoandorg.2004.10.001

Viktorelius M, Lundh M (2019) Energy efficiency at sea: an activity theoretical perspective on operational energy efficiency in maritime transport. Energy Res Soc Sci 52:1-9. https://doi. org/10.1016/j.erss.2019.01.021

Walsham G (1995) Interpretive case-studies in is research-nature and method. Eur J Inf Syst 4:74-81. https://doi.org/10.1057/ ejis. 1995.9

Wenger E (1998) Communities of practice: learning, meaning, and identity. Cambridge University Press, Cambridge

Publisher's Note Springer Nature remains neutral with regard to jurisdictional claims in published maps and institutional affiliations. 